\title{
The Analogical Practitioner: Relating Theory to Practice in Vocational Settings Using Problem Solutions, Causality, Design Patterns, Abstraction, and Case-Based Reasoning
}

\author{
Paul Kingsley \\ University of Liverpool/Laureate Online Education, United Kingdom
}

doi: 10.19044/esj.2017.v13n7p1 URL:http://dx.doi.org/10.19044/esj.2017.v13n7p1

\begin{abstract}
Universally true generalizations, from which specific conclusions can be deduced, are often unavailable to the practitioner, defined as anyone carrying out an occupation or profession. Theoretical shortcomings in the body of knowledge presented by academics can be counteracted by the practitioner using his or her knowledge of problem solutions. These can be stored as particular cases or as more generalized design patterns. They will typically contain information about cause-and-effect relationships and normative information about acceptable solutions. Use can be made of these solutions by employing reasoning by analogy and case-based reasoning. Similar problems require similar solutions. Cause-and-effect theory can be generated by practitioners using abstraction from particular cases, as an alternative to enumerative induction. The difference between this theory and that of the academic can be largely one of degree of generality. There is a continuum of cause-and-effect relationships at different levels of abstraction, which does not justify the abrupt separation of the academic and practitioner worlds, which has been encouraged by a reasonable interpretation of Bernstein's work. The study of exemplary problems in vocational education can be made more effective if it is accompanied by an examination of the actual outcomes of previously proposed solutions.
\end{abstract}

Keywords: Analogy, vocational education, design patterns, case-based reasoning, abstraction

\section{Introduction}

This paper aims to make a small contribution to the debate on the relationship between theory and practice in vocational settings. Academics may complain that not enough theory is taught in vocational education. 
Employers may feel that the theory which academics teach does not have enough relevance to their practical needs.

I take it that a conventional view of theory is that it is a systematically organised body of propositional knowledge which will typically contain universal generalizations, from which we can make deductive inferences about specific cases (Winch, 2010, p.104, p.186). If this deductive model were to be generally applicable, then how we apply theory to specific situations would be quite straightforward. The beauty of universally true generalizations is that they are true regardless of the particular circumstances. There is no need to worry about contexts because they do not affect the validity of the universal generalization. A deduction can be expressed as a syllogism:

1. The major premise: “All merryjumpers have four legs”.

2. The minor premise: "Henrietta is a merryjumper".

3. Conclusion: "Henrietta has four legs".

Unfortunately, there are good reasons to believe that such a convenient link between theory and practice is often not available to us.

\section{Nancy Cartwright and Models}

Nancy Cartwright argued that the fundamental laws of physics are distortions of reality, which is less tidy and less readily regimented than the laws themselves would suggest (Cartwright , 1983, p.162). She claimed that "models are essential to theory. Without them there is just abstract mathematical structure, formulae with holes in them, bearing no relation to reality" (Cartwright, 1983, p.159). "Laws, where they do apply, hold only ceteris paribus [other things being equal]” (Cartwright, 1999, p.4). Reality may just be a complicated patchwork of laws (the dappled world) (Cartwright, 1999, p.34). The theories of physics cannot typically be applied deductively (Cartwright, 1999, p.9). What is needed to relate theories to practice are causal laws, and these are usually embedded in models drawn up to serve a specific purpose, and the models are of limited scope (Cartwright, 1983, p.152). To advance the argument expressed in this paper, I simply note the importance of causal relationships in relating theory to reality, that models are of limited scope, and that the deduction of specific conclusions from theory is often not feasible.

In more recent years there has been a growing interest in scientific models rather than universal laws. Bailer-Jones (2009, p.206) combined a philosophical treatment of the subject with interviews of scientists. She argued that the emphasis on models is consistent with current scientific practice. Weisberg (2013, p.7) outlined the use of concrete, computational and mathematical models. He saw a model as an "interpreted structure that 
can be used to represent a real or imagined phenomenon” (Weisberg, 2013, p.15).

Multiple models may be required to describe a particular situation, depending on the purpose in hand. Weisberg followed Richard Levins in asserting that "The multiplicity of models is imposed by the contradictory demands of a complex heterogeneous nature and a mind that can only cope with few variables at a time; by the contradictory desiderata of generality, realism, and precision” (Weisberg, 2013, p.104). There is an emphasis on "structural and causal relationships within the target phenomenon" being included in the model (Weisberg, 2013, p.106). It should be noted how we decide whether a model applies to a particular situation; “...successful models are similar to their targets” (Weisberg, 2013, p.142). This is not a process of deductive inference. It is something closely akin to reasoning by analogy, which will be discussed later.

\section{Looking for a Cause}

Discontent with the body of theory can be detected in a number of intellectual disciplines. In the field of sociology, Robert Merton (1949/2012, p.531) had become disillusioned with "general theories of social systems which are too remote from particular classes of social behaviour, organization, and change to account for what is observed". He proposed the development of "middle-range theory" to guide empirical enquiry. He wanted to identify "social mechanisms" (causal relationships), the existence of which would be empirically testable. He hoped to get beyond high level theories, developed by people from different schools of thought, which were often seen as mutually exclusive and at odds with each other (Merton, 1949/2012, p.536).

This search for causal mechanisms (cause-and-effect theory) was carried on by researchers such as Hedstrom \& Vlikoski (2010). They noted that mechanism-based scientific explanations had increased in popularity "partly motivated by the shortcomings of the once hegemonic covering-law account of explanation” (Hedstrom \& Vlikoski, 2010, p.50). They noted that there is a shortage of the high-level covering laws from which we can deduce conclusions (Hedstrom \& Vlikoski, 2010, p.55). What this approach leaves open is the possibility that conclusions can be deduced from what may be thought of as mini-causal laws. By reducing the scope of the causal claims, it may be possible to build cause-and-effect theory at a lower level than was previously attempted.

In psychology, Pieter van Strien (1997, p.683) has argued for "the improvement of individual problem-situations with the help of low-level problem-directed theories" and that "the simple top-down model of practice as application of ready-made theories has long since been abandoned”. In 
outlining an alternative, he says that "practice is not, as in the top-down conception, the application of an already existing theory to the individual but the generation of a mini-theory of the individual case" (van Strien, 1997, p.685). Academic science "looks for truth: it approaches its object as something to be explained (explanandum). Practice, on the contrary, looks for improvement: it approaches its object as something to be changed (mutandum)” (van Strien, 1997, p.686). Important to making improvements will be the causal mechanisms that bring them about.

Joan van Aken (2004, p.219) felt that "there are serious doubts about the actual relevance of present-day management theory as developed by the academic community". There was a concern that the business world may be largely ignoring academic research in business schools. Van Aken thought that "all good theories are practical, but some are more practical than others". His aim was "the development of scientific knowledge to solve a class of managerial problems, in other words, the development of abstract knowledge” (van Aken, 2004, p.220). “A design exemplar is a general prescription which has to be translated to the specific problem at hand; in solving that problem, one has to design a specific variant of that design exemplar” (van Aken, 2004, p.227). Problem solutions imply the need for knowledge of the causes that can bring about the states of affairs regarded as solutions.

There are many reasons why it may be too optimistic to believe that vocationally useful specific conclusions can be regularly deduced from academic theory. Much theory is not in the form of empirical generalizations. For instance, in the field of education, Laurillard \& Ljudojevic (2011, p.89), pointed out that a lot of theory is in the form of principles of good practice which are difficult to interpret, and specific conclusions cannot be deduced from them. Key terms in a theory may be undefined or unclear. It may simply be difficult to know to which practical circumstances any given theory may apply. Some theory is in the form of universal generalizations that are not universally true. They are true in most cases or generally true. They are perhaps heuristics or rules of thumb. Most damaging of all, the theory may not provide details of causal relationships which will help address problems, or prevent problems from occurring. The theory may not be easily testable in practice. We might say of all of these limitations that there is a significant logical distance between the theory and its application in practice.

Implicit in a lot of the literature is the belief that modern vocational education is just a continuation of technical education. Engineering and construction no doubt still draw on a lot of hard science which explains how materials behave under certain conditions. However in the modern British economy, fewer and fewer people are involved in the manipulation of wood, 
metal, concrete and other materials to make things. They are engaged in public administration, banking and insurance, education, social care, retail, distribution/transport, IT, hospitality/tourism, and customer service. These are areas where it is less likely that there will be a significant body of theory from which conclusions can be literally deduced.

The criticism of academic theory by practitioners should not be interpreted too hastily as anti-intellectualism. It is often a pragmatic complaint that the practitioner is being handed damaged goods. The flat pack has arrived with a number of the key parts missing. The question of just how important a body of academic or scientific theory is in addressing specific vocational problems is, of course, an empirical issue, and the answer may differ depending on the domain. There is certainly scope here for empirical studies which start with the solutions to vocational problems and work backwards to see what part theory, viewed as a systematically organised body of knowledge, has played in their solution. The question then arises as to whether we are theoretically helpless in the cases where the organized body of theory does not obviously apply or, less charitably, where it is full of holes.

\section{Bernstein and Recontextualisation}

The scepticism about the adequacy of a deductive account of how theory is related to practice has created a search for alternative explanations. A number of academics, particularly those who have been associated with the University of London's Institute of Education, have believed that Basil Bernstein provided some of the answers.

He contributed two central ideas. Firstly, that knowledge is separated into vertical and horizontal realms or "discourses". The vertical has sometimes been associated with theory and academia; the horizontal with the world of practice. Secondly, that the way vertical knowledge is applied to a particular situation (to practice) is through a process of recontextualisation.

"Briefly, a vertical discourse takes the form of a coherent, explicit and systematically principled structure, hierarchically organised, as in the sciences, or it takes the form of a series of specialised languages with specialised modes of interrogation and specialised criteria for the production and circulation of texts, as in the social sciences and humanities" (Bernstein, 1999, p.159). “A horizontal discourse entails a set of strategies, which are local, segmentally organised, context specific and dependent, for maximising encounters with persons and habitats" (Bernstein, 1999, p.159). "Thus, in the case of horizontal discourse, its 'knowledges', competences and literacies are segmental. They are contextually specific and 'context dependent', embedded in on-going practices, usually with strong affective loading, and 
directed towards specific, immediate goals, highly relevant to the acquirer in the context of his/her life" (Bernstein, 1999, p.161).

In the horizontal dimension, the individual has repertoires of strategies, and the community has reservoirs of such strategies (Bernstein, 1999, p.159). Not surprisingly in a vocational context, the vertical domain, often identified as the preserve of academics and scientists, has come to be seen as the source of knowledge, whereas the horizontal is sometimes seen as the home of skills with narrow applicability.

Michael Young (2006) tried to maintain Bernstein's framework, but only at the expense of caricaturing the practitioner's "horizontal" domain. Vocational knowledge was said to be "often uncodifiable" (Young, 2006, p.113); “cannot be made explicit” (Young, 2006, p.119); is produced “"in a context' - it is never entirely context free” (Young, 2006, p.114-115); and "embodies no explicit principles" for transferring knowledge across occupational sectors (Young, 2006, p.118).

Gamble (2006, p.89) argued that "Context-independent meanings refer to that which exists only in abstract form. Context-dependent meanings refer to meanings that derive from concrete events or experiences that have actually happened in a specific time and place”.

Of course, where knowledge comes from is not particularly relevant. A very general theory can be produced after studying very specific events. All theory is applicable in only certain contexts. How many contexts are involved is only a difference of degree. As we shall see, a specific event which causes another specific event in a specific context is always generalizable. Further, there is no reason why a practitioner's knowledge of the causal relationships that can help solve problems cannot be made explicit. These causal relationships are often relevant to multiple occupational domains.

As David Guile (2014, p.80) put it, "every type of human activity is encountered and employed contextually. This does not mean, however, that forms of activity, or for that matter resources, are context-bound: human intentionality allows them to be used in different ways in different contexts”. There is a "commingling of the theoretical and everyday, rather than moving between separate conceptual and practical spheres” (Guile, 2014, p.80). We are always capable of seeing the general in the particular (Weinreb, 2005, p.124).

Bernstein's analysis threatened to build a new Berlin Wall between theory and practice. It left academia open to a charge of occupational selfinterest. Propositional knowledge was primarily its preserve and, by comparison, the knowledge possessed by the practitioner was a very poor thing and of little general interest. It portrayed academia in the best possible 
light, and was in danger of encouraging a rather condescending attitude towards the practitioner.

Starting from this analysis it became very difficult to specify how knowledge actually passed from theory to practice. Bernstein suggested that this was through a process of recontextualisation. The problem is that this term is never given a satisfactory definition. Bernstein tends to define it in terms of other concepts which are themselves undefined or not in common use. The overwhelming impression is that the word recontextualisation expresses a praiseworthy aspiration to relate theory to particular situations, without ever providing enough jargon-free guidance to allow a keen student to actually go out and recontextualise something.

As a sociologist, Bernstein was probably wearied by the battles of the ideological factions in his subject, coming to see these factions as speaking different languages. This coloured his perception of what he saw as horizontal knowledge. He wrote, almost wistfully, "I suppose that the view would be markedly improved if the discursive centre of gravity shifted from the specialised languages to issues of empirical description: a shift from commitment to a language to a problem and its vicissitudes" (Bernstein, 1999, p.170).

Here Bernstein saw the way ahead through a glass darkly. The focus on problems would have led him to search for the causal mechanisms necessary to address these problems, and that may in turn have punched a hole in the Berlin Wall between theory and practice by showing that practitioners just might be the guardians of some cause-and-effect theory. Causality can be the bridge which relates theory to practice, and brings closer the worlds of the academic and the practitioner.

Subsequent writers, labouring under the intolerable burden of Bernstein's framework, have nevertheless provided a number of clues about what recontextualisation may have meant. David Layton (1993, p.58) suggested that sometimes we have to adjust the level of abstraction. This is a promising line of enquiry which will be pursued later in this paper. Jim Hordern (2014, p.23) probably referred to the same issue as Layton in writing about “'generalisation' and 'particularisation”,. He also highlights the selection of knowledge for a particular purpose (Hordern, 2014, p.24). In this paper that purpose will be primarily to address a particular problem.

\section{Herbert Simon and Design Science}

Herbert Simon (1981, p.xi) believed that "Engineering, medicine, business, architecture, and painting are not concerned with the necessary but with the contingent - not with how things are but with how they might be in short, with design”. Expressed slightly differently, these design sciences are concerned with how things ought to be in order to attain certain goals 
(Simon, 1981, p.7). Sometimes the production of artefacts is seen as necessary to achieve these goals (Simon, 1981, p.133).

The concepts of design and artefact are, however, not defined in a restrictive way. "Everyone designs who devises courses of action aimed at changing existing situations into preferred ones. The intellectual activity that produces material artifacts is no different fundamentally from the one that prescribes remedies for a sick patient or the one that devises a new sales plan for a company or a social welfare policy for a state” (Simon, 1981, p.129).

Building on Simon's argument, I should like to say that what is of value here is the design of a solution to a problem. Central to the design of a solution will be an understanding of causal relationships. These causes may be generative (bringing about a new situation) or preventative (maintaining the current situation in a safe, or otherwise desirable, state). The design of solutions should include diagnostic problems where, given a series of known effects, the practitioner judges the most likely causes (a form of abductive reasoning or reasoning to the best explanation) (Josephson \& Josephson, 1996; Walton, 2004). It should also include plans to meet a need, economic or otherwise. This highlights the causative aspect of problem solutions.

There is also a normative aspect, which sets the goals we are aiming for in trying to solve a problem and, indeed, defines what is a problem and what is not.

\section{Means and Ends}

Simon had what is often described as an instrumentalist approach to this normative dimension. The designer is presented with some goal (or end) and then designs the most efficient means of achieving that goal or of maximizing the value of some variable. Simon (1981, p.135-136) uses some unusual terminology, but fortunately he also provides a means of translating it into more familiar language (shown in the square brackets). "Problem: Given the constraints [costs] and fixed parameters [laws], find values of the command variables [means] that maximize the utility [ends]."

He acknowledges that an "ought" cannot be derived from an "is" (Simon, 1981, p.8). However, a discussion about the appropriateness of goals is avoided by treating the ends to be pursued as simply given to the designer. The design process is, seemingly just a technical task of selecting the most efficient means of achieving some end, taking account of all the circumstances.

There are two objections to this approach, one economic and the other more ethical. Both require that the end be regarded as provisional, and likely to change or be abandoned after evaluating costs and consequences.

In vocational education literature there is a strong bias towards production values. Students are to acquire the knowledge and skills which 
will permit them to produce goods and services. Given less emphasis is the economic and marketing knowledge which will tell the employee why he or she is being paid to exercise skills, and the factors that will influence whether or not he or she will go on getting paid.

In economic terms, goals or ends are dictated primarily by customers or other stakeholders, although business can always be declined on the grounds of conscience. Goods and services are produced and (usually) sold when there is a want backed up by a willingness and ability of someone to pay. All economic demand is demand at a particular price. An evaluation of costs and consequences will not only determine the best means to achieve some pre-determined goal. It will determine what that goal is. In economics, the goal can be adjusted or abandoned after costs and consequences have been evaluated.

There is also an ethical dimension. In evaluating costs and consequences, we may find that the end can be achieved, but only at a terrible human cost which is politically and ethically unacceptable. It may also be a public relations disaster. As the likely negative effects pile up, the chances of the end being pursued decrease. The end is likely to be radically amended, or scrapped.

There is a supplementary point which needs to be made. A problem is always a problem for someone. What one person regards as a problem to be solved, another person may see as no problem at all. The same is true of solutions. A new state of affairs may be regarded as a solution by one person and not by another. For this reason, a problem is never simply a state of affairs, although we may sometimes be tempted to think that it is. It has the status of a problem only because of its relationship with someone's values.

People may not be able to say in advance what they want. They may only be able to recognize it when they see it. This is a notorious problem for systems analysts who try to get customers to specify the kind of computer system they want. Vocationally, the goal is often not something that is fixed in advance, but is something that is discovered by a process of presenting potential solutions. Ultimately the goal may be best expressed in terms of pleasing the customer or some other stakeholder, and which artefact or state of affairs will achieve that is initially unclear. An appreciation of likely customer values would be useful here.

Whether it be on economic or more ethical grounds, a purely instrumental view, where practitioners as a whole are concerned only with means rather than ends, is not sustainable. Under the division of labour, certain individuals may be relieved of the responsibility of thinking about ends, but this is likely to be counter-productive. The more people who are worrying about the needs of the customer, and the consequences of the practitioner's actions, the better. 
The approach suggested here is somewhat similar to that of John Dewey's. The means and ends should be regarded as a combined package. The decision is therefore always between one means-end package and another. This should help us not to pursue some utopian goal obsessively without regard to the terrible costs and consequences (Dewey, 1939, p.24).

\section{Donald Schön}

The work of Donald Schön (1991) was something of a reaction against those who stressed the dominant role of academic and scientific knowledge in the work of the practitioner. He was concerned with professionals rather than all vocational occupations, but his views are very relevant to some of the themes set out in this paper.

He argued that "The situations of practice are inherently unstable", and this also applied to the body of knowledge required by practitioners (Schön, 1991, p.15). They were faced with "problematic situations characterized by uncertainty, disorder, and indeterminacy" (Schön, 1991, 16). What was needed was "an artful practice of the unique case" rather than "application of established techniques to recurrent events" (Schön, 1991, p.19).

After a dramatic opening to his book, which questions the value of a body of theory to someone facing unique problems, Schön outlined a position that was not quite consistent with the sensational headlines. He finally conceded that "In some parts of practice - medicine, engineering, dentistry, management, for example - practitioners can and do make use of knowledge generated by university-based researchers" (Schön, 1991, p.308).

Although a mysterious reflection-in-action was seen by Schön as the answer to addressing problematical situations, the actual examples he gives see the master practitioner drawing on a body of past experience. Situations may be technically unique, but they are usually sufficiently like previous problematical situations to make use of a body of knowledge.

"Faced with some phenomenon that he finds unique, the inquirer nevertheless draws on some element of his familiar repertoire which he treats as exemplar or as generative metaphor" (Schön, 1991, p.269). We might say that the practitioner uses reasoning by analogy.

"Organizations, furthermore, are repositories of cumulative built-up knowledge: principles and maxims of practice, images of mission and identity, facts about the task environment, techniques of operation, stores of past experience which serve as exemplars for future action. When a manager reflects-in-action, he draws on his stock or organizational knowledge, adapting it to some present instance" (Schön, 1991, p.242). That stock of knowledge could include knowledge about cause-and-effect relationships. 
Looking past the headlines and the jargon, the process now seems to be more recognizable.

Schön did rightly criticize a view that "Practical knowledge was to be construed as knowledge of the relationship of means to ends. Given agreement about ends, the question, 'How ought I to act?' could be reduced to a merely instrumental question about the means best suited to achieve one’s ends” (Schön, 1991, p.33). The practitioner “does not keep means and ends separate, but defines them interactively” (Schön, 1991, p.68). This issue has already been addressed in this paper. However, it is not altogether clear that Schön acknowledged that if the practitioner is going to be concerned with both means and ends, he or she will need a lot of knowledge about causal relationships to compare various means-end combinations. This knowledge may come from a body of academic theory, or from the practitioner's past experience.

\section{Design Patterns}

Christopher Alexander, working in the field of architecture, is often credited with being one of the first people to write about design patterns. He and his colleagues gave this definition: "Each pattern describes a problem which occurs over and over again in our environment, and then describes the core of the solution to that problem, in such a way that you can use this solution a million times over, without ever doing it the same way twice" (Alexander et al, 1977, p.x).

Here is another definition from the field of education: "In our view a design pattern is a semi-structured description of an expert's method for solving a recurrent problem, which includes a description of the problem itself and the context in which the method is applicable, but does not include directives which bind the solution to unique circumstances. Design patterns have the explicit aim of externalizing knowledge to allow accumulation and generalization of solutions and to allow all members of a community or design group to participate in discussions relating to the design” (Mor \& Winters, 2006, p.66).

There may be a significant logical distance between theory and practice. Theoretical principles may need a great deal of additional work before they can be applied to vocational problems. In looking at the body of theory that has been handed to us, we may feel like the person who has been promised lamb chops, only to be presented with a live sheep and a meat cleaver. We are left with too much work to do.

What perhaps we need are methods of storing more highly processed information that focus on problem solutions. These data structures will need to be able to store vocationally relevant causal relationships as well as 
courses of action (means-end packages) which have been considered to be acceptable.

Mason (1994, p.188, p.192) wrote about a practitioner having a covenant with reality and a covenant with values. That applies here. We need a repository for causal relationships and values. The candidate for consideration in this paper is the design pattern.

Inspired by Simon's suggestions, there has emerged a very healthy design science literature (Wieringa, 2014; Johanneson \& Perjons, 2012; van Aken et al, 2011; Hevner et al, 2004; Dresch et al, 2015). The main practical goal of these design scientists has been to create a viable alternative to conventional academic research, particularly at a postgraduate level. The typical project aims to produce an innovative design, possibly to make the equivalent of a unique contribution to knowledge. There are some similarities between design science and the field of educational design research (McKenney \& Reeves, 2012; Van den Akker et al, 2006).

Parallel to this development, and to a great extent independent of it, has been an intellectual movement promoting the value of design patterns. This tradition concentrates rather more on tried and trusted solutions to problems that can be reused by practitioners.

The strength of the design pattern concept is that there is no one dominant structure which has imposed itself on all fields of inquiry, regardless of their particular needs. A selection of suggestions about structure is set out in Table 1 below. They come from architecture (Alexander, 1977), computer programming (Gamma et al, 1994), and education (Bergin, 2012; Laurillard, 2012).

Table 1: What Is in a Design Pattern? (Kingsley, 2015, p.66)

\begin{tabular}{|c|c|}
\hline Author & Structure of the Design Pattern \\
\hline Alexander (1977) & $\begin{array}{l}\text { Short Name, Rating, Sensitizing Picture [something } \\
\text { visual], Context Description, Problem Statement, } \\
\text { Text with Examples and Explanations, Solution } \\
\text { Statement, Sketch, Further References }\end{array}$ \\
\hline Gamma et al (1994) & $\begin{array}{c}\text { Pattern Name and Classification, Intent, Also Known } \\
\text { As, Motivation (Forces), Applicability, Structure, } \\
\text { Participants, Collaboration, Consequences, } \\
\text { Implementation, Sample Code, Known Uses, Related } \\
\text { Patterns }\end{array}$ \\
\hline Bergin (2012) & $\begin{array}{c}\text { Problem/Issue, Audience/Context, Forces, Solution, } \\
\text { Discussion/Consequences/Implementation, Special } \\
\text { Resources, Related Patterns, Example Instances, } \\
\text { Contraindications, References }\end{array}$ \\
\hline Laurillard (2012) & $\begin{array}{l}\text { Origins, Summary, Topics, Learning Outcome, } \\
\text { Rationale, Duration, Learners, Setting, Resources } \\
\text { and Tools, Learning Cycles, Designer’s Reflection }\end{array}$ \\
\hline
\end{tabular}


A flexible structure such as a design pattern is capable of accommodating universal generalizations, practitioner cause-and-effect theory, references to models and specific cases, details of skills needed to execute the solution, and a rationale for the values which lead to something being regarded as a problem, and something else subsequently being regarded as a solution. Identifying an appropriate solution will involve an analogical ability to recognise a relevant pattern.

\section{A New Look at Theory and Generalizability}

I asked whether we are theoretically helpless in the cases where the organized body of theory does not obviously apply. Fortunately the answer is no, because where the contribution of largely academic and scientific theory ends, practitioner theory can take over.

Alongside the definitions of theory that would be recognized by academics, the Oxford English Dictionary provides this definition: "A conception of something to be done, or of the method of doing it; a systematic statement of rules or principles to be followed”. In the spirit of this definition, I should like to suggest that in vocational matters, a central need is a theory about how to solve a problem. This should involve a covenant with reality and a covenant with values.

It has been suggested that the design pattern can be a suitable data structure for storing details about problem solutions. It could therefore be argued that design patterns are suitable structures to contain a theory about how to solve a problem.

The challenge then is to prevent this becoming the solution to just a specific problem in a specific set of circumstances. How do we generalize to other cases? The first step is to shake off the shackles imposed by a very narrow concept of generalizability. One definition of "generalize" is given by the Oxford English Dictionary: “To make (a proposition, theorem, etc.) general in form or application; to extend (a proposition, theorem, etc.) so as to cover a wider or more general class of cases". The troublesome part is that about making something general in form to extend its application. This is one way, but only one way in which we generalize. The difficulty arises if we focus obsessively on propositions with a general form, such as "All merryjumpers have four legs”. Universal generalizations, and subsequent deductions from them, provide a perfectly acceptable way of applying theory to numerous cases. In view of the frequent shortage of universally true generalizations in particular domains, it is fortunate that there are alternatives.

Consider statistical generalization. Statisticians make generalizations from a sample to a population. Emphasis may be placed on randomization, that is the way in which the sample has been randomly selected. However, 
this is only a means to an end. If we have doubts about the random nature of the selection, then we are likely to check whether a sample of people is similar to the relevant population in terms of things such as age profile, gender composition, geographical distribution, and social class. What we do is to check that the sample and the population are similar in terms of known values of certain variables. We are then convinced that the sample is likely to be similar in terms of the values of other variables which we are investigating. This may refer to the proportion of people who will vote for a particular option in a referendum, or the percentage who will like the company's new product. This use of inference by similarity is a form of reasoning by analogy (analogical reasoning). The importance of this form of reasoning as an alternative to deduction will soon become clear.

\section{Generalizing the Particular}

Winch acknowledges that theory can be formed by induction. This involves "the production of generalized propositions through the accumulation of conclusions derived from experience” (Winch, 2010, p.186). This is often known as enumerative induction. By observing lots of swans, we draw up a proposition in a general form which we believe applies to all swans. This is perfectly true, but it is not the sole means by which we can generalize from the particular case.

If we envisage the particular case as something akin to the observation of the properties possessed by a single swan or merryjumper, then it becomes very difficult to construct any theory about why experience is important to a practitioner. Plenty has been written about expertise, viewed primarily as the development of skills or knowing how (e.g. Winch, 2010), but knowledge of particular cases is often seen as being of minor value.

This paper has stressed the importance of causal relationships. Fortunately, knowledge about the cause of a specific event is nothing like knowledge of one particular swan. A single causal event always forms the basis for generalization. Even though we are not sure which causal mechanism is operating, we do believe that if exactly the same set of circumstances occur again, they will result in the same effect. We believe this for roughly the same reasons that we believe in the repeatability of scientific experiments if the conditions are exactly the same.

\section{Case-Based Reasoning, Problem Solutions and the Importance of Experience}

The field of case-based reasoning takes this one step further. In this tradition, a case is a solution to a problem. Case-based reasoning argues simply that the same problem is likely to have the same solution, and that 
similar problems are likely to have similar solutions. These are not infallible methods of reasoning, but they are reliable.

In more recent years, case-based reasoning has been seen as something that will be carried out by computers, and human uses of such reasoning, outside the field of legal precedent, have been somewhat neglected. Perhaps now is the time to end that neglect. Whoever or whatever is doing the reasoning, a case base (database) is built up by storing solutions to problems arrived at by humans. The cases are often referred to in this tradition as experiences, reflecting the fact that they are usually derived from the experience of experts in a particular field.

Ian Watson has sketched out a number of the basic ideas. He asked "why resolve a problem each time if someone has already solved it? Would it not be simpler to remember the solution?” (Watson, 1997, p.11), and thought that "in general people understand and trust precedents but are less comfortable with abstract rules" (Watson, 1997, p.48). He argued that "we do not always reason by using rules and first principles. Very often we solve problems by relying on our experience of similar problems we have encountered in the past” (Watson, 1997, p.197).

Regardless of whether they have heard of case-based reasoning or not, this is what experienced practitioners do all the time. A novice, asking a more experienced colleague how to solve a problem, is quite likely to be told, "I remember a case like this. The problem was solved in the following way. Perhaps that may be of use in getting to grips with your problem”. This approach paves the way for an explanation of why experience is important. Experts accumulate a store of problem solutions. The more problem solutions they possess, the easier it is to find a problem that is similar to the current problem with which they are faced.

Returning to the specifics of case-based reasoning, Janet Kolodner (1992), in one of the classic papers on the subject, outlined more of the central concepts. She stressed that this is about not just copying solutions, but “adapting old solutions to new problems" (Kolodner, 1992, p.3). Adaptation of previous solutions "is almost always preferable to generating a solution from scratch” (Kolodner, 1992, p.8). The cases used should include solutions that were not a success, to warn of possible failures (Kolodner, 1992, p.4) and of possible problems that may arise (Kolodner, 1992, p.7). Feedback is important in order to evaluate solutions (Kolodner, 1992, p.6). Solutions should be testable.

"A case-based approach ...requires a retrieval mechanism that can retrieve similar cases, an adaptation mechanism that must be quite creative, and a validation mechanism that can decide if a proposed explanation has any merit" (Kolodner, 1992, p.14). "In general, cases are useful in constructing arguments and justifying positions when there are no concrete 
principles or only a few of them, if principles are inconsistent, or if their meanings are not well-specified” (Kolodner, 1992, p.16). They will therefore be useful where the theory handed down to practitioners is incomplete.

"CBR [case-based reasoning] relies on the concept of similarity, which focuses on the attributes shared by two entities. Analogy is based on comparing the abstract structure of two entities” (Richter \& Weber, 2013, p.534). In a vocational setting, of particular interest will be two cases with a similar causal structure. Fortunately, that aspect of case-based reasoning has been partly carried forward in the literature on reasoning by analogy.

\section{Abstraction, Universalizability and Generalizability}

There are two important aspects to theory which I want to highlight scope and universality. All generalizations have a wider or narrower scope. In our earlier generalization, a claim was made only about the number of legs possessed by merryjumpers. The claim did not extend to any other creature. We might say that its scope was limited to the class of merryjumpers. On the other hand, a claim was made about all merryjumpers. It was therefore a universal claim.

In order to make this important distinction, it may be useful to use the term generalizability to apply to the scope of a theoretical claim, and universalizability to apply to the extent to which it approaches $100 \%$ applicability within the specified scope. There will often be a trade-off between these two variables. The broader the scope of our theory, the less likely it is to apply to all of the cases within the scope of that theory.

Although we may often think of abstraction as being first and foremost associated with the more general, this is really just a side effect. The key characteristic of abstraction is the loss of information (Kohls \& Wedekind, 2011, p.13) or information reduction (Saitta \& Zucker, 2013, p.118). The use of abstraction tends to increase generalizability in the sense I have used it, in that it removes a lot of detail and hence makes a claim potentially applicable to a greater number of cases. Where abstraction is pushed too far, universalizability, in my use of the word, will suffer. There will be more and more exceptions to a relevant theoretical principle.

Kolodner (1992, p.20) pointed out situations where generalized cases could be stored when several related cases all suggest the same solution. A degree of abstraction can be applied to particular cases (Bergmann \& Wilke, 2005; Bergmann et al, 2006). Kohls \& Wedekind (2011, p.13) thought that design patterns "are not fixed designs nor are they very abstract designs. Patterns are at a medium level of abstraction”. Design patterns will therefore be of use in storing generalized cases. This is the second reason why the practitioner is not left helpless in the face of deficiencies in academic or scientific theory. He or she can develop theory incrementally from the 
bottom up through the use of abstraction. The practitioner may, of course, use enumerative induction to start to create theory, but he or she has other alternatives. By removing information that is specific to a particular situation from the individual case (especially specific information about a causal relationship), generalization can take place without enumerative induction.

Each time information loss takes place, the generalized cases have to be tested to see if they provide a reasonable description of reality. What may be found on occasions is that reasoning from the generalized case will throw up too many instances where e.g. the effect does not follow from the stated cause. The cause-effect relationship holds only at a less abstract level of representation, where more detail is required to qualify the situations in which the causal relationship applies. It would therefore be a mistake to believe that abstraction is always desirable, or that it should be an irreversible process. At times we may need to reinsert some details to avoid violating the truth. It is necessary sometimes "to be able to climb back down the ladder of abstraction and judge where to stop, i.e. recognise which level is most appropriate for a specific technological purpose” (Layton, 1993, p.58).

In general, if the truth about a particular domain can be captured in a few very broadly applicable principles, from which particular conclusions can be deduced, then a high level of abstraction may be appropriate. However, if a vocational domain can most accurately be described by a very large number of principles with limited scope, then abstraction will be less of a virtue. We may say of the latter type of domain that the devil is in the detail. If relatively small changes in circumstances can prevent the effect following the hypothesized cause, then it may be more productive to reason from a particular case.

The difficulty here is that very general theory is usually not taught alongside a large number of cases. At best, a small number of examples will be used to illustrate the principle being presented. Depending on the background of the teacher, the large number of cases available to the expert practitioner may or may not be accessible to the academic. They are certainly not likely to be available to the student (except, perhaps, through some kind of apprenticeship alongside an expert practitioner). A lot of theory is simply presented to students with the detail more or less permanently discarded. On the deductive model, the detail is not important. Where the theory falls rather short of universal applicability, we often need to get the detail back.

It will be useful at this point to borrow an idea from image compression to make a distinction between lossy and lossless abstraction. Lossless abstraction will involve the retention of all the information temporarily discarded during the abstraction process. It can therefore be reinserted into theory if the degree of abstraction is found to be too high to 
describe reality accurately. Expert practitioners typically engage in this kind of abstraction. Lossy abstraction will involve the more or less permanent discarding of information in the belief that the theory is sufficient to support a deductive approach in which particular conclusions can be derived from universal generalizations. This kind of abstraction is more characteristic of academics.

I have argued that, in vocational contexts, the main priority is to come up with a theory about how to solve a problem. Central to this process will be the identification of cause-and-effect theory. That theory may be of greater or lesser scope, depending on the susceptibility of a particular vocational domain to being described accurately by broad generalizations. The causal mechanisms will form a continuum ranging from the very broad claims in what academics and scientists would see as an organized body of theory, down to the causal principles of the practitioner's world which operate in a narrower range of specific circumstances. There is no justification here for building a Berlin Wall to separate academic and practitioner theory.

\section{Abstraction and the Normative Use of Cases}

Reasoning from legal precedent is used in cases where relevant statute law does not exist, or where the meaning of certain terms in legislation needs to be defined in case law. It provides clues about how abstraction can be applied to the normative aspects of problem solutions. It has been argued that "the probability that a court will decide a new case in the same way as would the court which decided one of the cases cited becomes less and less as the differences between the facts of the two cases increase" (Cross, 1968, p.39). Lawyers will maintain that there are material differences between the cases which mean that any principle established in an earlier case does not apply in a different case.

The principles or rules used by judges are deemed to be valid in a particular set of circumstances. They are not universal generalizations "rules need to be qualified" (Cross, 1968, p.190). Weinreb (2005, p.88) points out that "when a court wants to overrule a prior case without quite saying so, it declares that the rule of that case 'is limited to its own facts"”.

"Precedent is said to be a function of equality by treating like cases alike...Legal certainty, predictability and previsibility are considered cardinal principles” (Jacob, 2014, p.13). This approach may be applied directly to certain vocational situations, such as when a shop deals equitably with customer complaints, or where a public authority treats applications for services in a similar manner in similar circumstances. Previous business decisions may also just give an indication of what was deemed to an acceptable solution to a problem. Faithful to the covenant with values, a 
design pattern can be used to store acceptable outcomes and the means used to bring them about (means-end packages).

We can see, however, that "reasoning by precedent usually involves bouncing between a general idea and its particular application” (Jacob, 2014, p.11). The law does arrive at general (but not universal) principles and this means that we have "abstraction beyond the concrete case” (Jacob, 2014, p.74). However, there are cases in which these general principles break down. Precedents, involving principles and specific circumstances can be seen “as legal devices of medium-level abstraction” (Jacob, 2014, p.80). Where a principle overreaches itself, claiming application in too wide a range of cases, it is time to climb back down the abstraction ladder and limit the principle to a narrower range of circumstances.

Similarly, in storing valuable solutions in a design pattern, we may have to acknowledge that they will only be seen as valuable in certain circumstances. There are two obvious things that could go wrong. A change in circumstances could mean that a cause would no longer bring about the desired effect. Alternatively, different circumstances could generate different costs and consequences which would negate the value of the solution used in a previous case. This may lead to the search for another past case which is more similar to the new problem under consideration.

Case-based reasoning is viable in dealing with legal precedents because the law uses lossless abstraction. Legal decisions are written up and stored in searchable databases. Some abstraction takes place in arriving at general principles, but because none of the specific cases have been thrown away, they are always available to those who need to reason by analogy.

\section{Wittgenstein's Games and the Diminishing Influence of Deduction}

Ludwig Wittgenstein (1958, pp.31-32) asked what it is that all games have in common. The answer was - nothing. He suggested that there was a family resemblance between games. "And we extend our concept of number as in spinning a thread we twist fibre on fibre. And the strength of the thread does not reside in the fact that some one fibre runs through its whole length, but in the overlapping of many fibres" (Wittgenstein, 1958, p.32).

Wittgenstein was challenging the idea that we always classify things (subsume them under a particular concept) by the use of necessary and sufficient conditions which we can use to deduce conclusions. In doing so, he effectively challenged the importance of deduction in our lives. What was needed in many cases was a means of identifying similarity.

Eleanor Rosch highlighted the empirical work being carried out in the field of psychology that was inspired by Wittgenstein's insight. Her suggestion was that we tend to form a mental prototype, an idea of what a typical X should be like. These prototypes would be the clearest cases or best 
examples which would bear a family resemblance to other members of the category. A particular instance would be classified as an $\mathrm{X}$ if it was similar to the prototype. Some instances would be seen as better examples of an $\mathrm{X}$ than others depending on how close to the prototype they were (Rosch \& Mervis, 1975). The thought process was more analogical than deductive.

A popular alternative to this theory, which also has some empirical support, is based on exemplars. Nosofsky (2011, p.18) explained that "people represent categories by storing individual exemplars (or examples) in memory, and classify objects based on their similarity to these stored exemplars...This exemplar view of categorization contrasts dramatically with major alternative approaches that assume that people form abstract summary representations of categories”. Prototype and exemplar theories are consistent with the view set out in this paper that people regularly use both abstraction and case-based reasoning (Didierjean \& Cauzinille-Marmèche, 1998). In both cases we have to think analogically to detect similarities.

The main point of relevance to this paper is that reasoning by analogy is not some peripheral feature of human thought. It is absolutely central. We are constantly using it every day. As Hofstadter \& Sander (2013, p.3) claim, "without concepts there can be no thought, and without analogies there can be no concepts”.

\section{Analogy and Causality}

We have seen that a practitioner may recall that a current problem is similar to a previously solved problem. The similarity is established by analogical reasoning, but it is not just any kind of similarity.

"Two situations are analogous if they share a common pattern of relationships among their constituent elements, even though the elements themselves differ across the two situations. ... Typically one analog, termed the source or base, is more familiar or better understood than the second analog, termed the target. By 'better understood' we mean that the reasoner has prior knowledge about functional relations within the source analog beliefs that certain aspects of the source have causal, explanatory, or logical connections to other aspects” (Holyoak, 2013, p.234). Moving beyond the question of categorization, to the area of finding solutions to problems, the psychology literature exhibits a strong consensus that it is these structural similarities which lead to the most productive and reliable uses of reasoning by analogy (Gentner \& Colhoun, 2010; Lee \& Holyoak, 2008; Goswami, 2001; Ross \& Kennedy, 1990; Holyoak \& Thagard, 1995).

This conclusion is endorsed in a thorough philosophical study of analogy (Bartha, 2010). Belated philosophical interest in analogy is also evidenced in Shelley (2002) and Bach (2012). For our purposes, the most important structural relationship is one involving causality. 
"Analogies are employed in all sciences to demonstrate the plausibility of hypotheses" (Bartha, 2010, p.2). This was confirmed in observation studies of molecular biologists and immunologists' lab meetings (Dunbar \& Blanchette, 2001; Dunbar, 2001). When asked later what had suggested a solution to a problem, scientists had often forgotten that an analogical argument had played a major role (Dunbar, 2001, p.318-319). They had climbed a ladder and then kicked it away. This tendency to forgetfulness may partly explain why we underestimate the significance of analogy.

"The importance of relational knowledge to successful analogising may also explain why analogies are a good correlate of IQ. Children with a deeper conceptual understanding of a given domain will have represented more of the relationships that hold within that domain, and thus will be able to solve more complex analogies set within that domain" (Goswami, 1992, p.117). The same is true of experts within an occupational domain. The more knowledge they have of causal relationships, the better they will be at solving problems by analogical reasoning.

\section{Studying Problems Without Solutions}

There are educational strategies which involve the study of problems. One of these is the case method, closely associated with the Harvard Business School. It is sometimes also referred to as a case study method, which is a little confusing, as the term case study is also associated with a research methodology involving things like surveys, interviews, observation and the examination of documents (Rippin et al, 2002; Yin, 2003).

In the Harvard version, the emphasis is on studying real world business problems. "A case is a partial, historical, clinical study of a situation which has confronted a practising administrator or managerial group" (Barnes et al, 1994, p.44). Students will discuss these problems and suggest their own solutions. Typically, they will not study actual outcomes. The success or failure of proposed solutions implemented by a real business would not be a major focus of this approach.

Closely related to the case method is problem-based learning, developed by Howard Barrows while he was teaching medical students at McMaster University in Canada. "PBL [problem-based learning] is an instructional (and curricular) learner-centred approach that empowers learners to conduct research, integrate theory and practice, and apply knowledge and skills to develop a viable solution to a defined problem...students work in collaborative groups to identify what they need to learn in order to solve a problem, engage in self-directed learning, apply their knowledge to the problem” (Savery, 2015, pp.7-8). 
Focusing on ethical problems in education, Meira Levinson and Jacob Fay proposed the study of "normative case studies, which we define as richly described, realistic accounts of complex ethical dilemmas that arise within practice or policy contexts, in which protagonists must decide among courses of action, none of which is self-evident as the right one to take" (Levinson \& Fay, 2016, pp.5-6). This approach is partly inspired by a scepticism "that any meaningfully complex problems of ethical practice can be reliably solved by the application of a very general theory" (Levinson \& Fay, 2016, p.6).

Each of these approaches has major merits. The study of realistic problems can certainly help to bridge the gap between theory and practice. There may, however, be a major piece of the jigsaw missing. The study of real life outcomes of proposed solutions would enhance this kind of learning. Howard Barrows himself acknowledged the importance of the accumulation of past solutions in improving clinical diagnosis.

"If a clinician has had extensive experience with certain patient problems, he will easily recall the most effective hypotheses or diagnoses when confronted by that problem" (Barrows \& Pickell, 1991, p.8).

The difficulty may be that a student will not have sufficient experience to know what information to look for or have sufficient knowledge of causal mechanisms to arrive at a viable solution. The danger is that, in the absence of a study of actual outcomes of proposed solutions, the student will simply suggest a strategy that goes untested.

It is not necessary that students be presented with actual outcomes of their kind of solution at the beginning of the exercise (although they could be). These can be presented at the end as part of the process of evaluating a proposed student solution. This is also true of suggestions about how to address ethical issues. A proposed solution to an ethical dilemma may be based on little more than good intentions. It can be extremely helpful to show, as part of the evaluation, that solutions similar to that proposed by students have, in the past, had a particular outcome. This will be useful in assessing the costs and consequences of various options, and making students aware of perhaps unforeseen causal relationships.

Problem solving may, in part, be a generic skill. It is also, however, influenced by the experience of the problem solver. The more domain specific solutions to problems a practitioner possesses, the easier it will be solve new problems (Lancaster and Kolodner, 1987). Fortunately, it is not always necessary for the practitioner to learn all of this from his or her own experience (Orr, 1996; Lucas et al, 2012; Kolodner, 1997). It can also be learned from more experienced practitioners, implicitly or explicitly articulated in design patterns. 
Does a study of specific problems enable generalization and move us beyond the present and the particular (Bailey, 1984)? It does if they are exemplary. We noticed that in statistics, a sample is generalized to some wider population because the sample is similar in relevant respects to that population. If a specific problem is very similar to many other problems which a practitioner is likely to face, it could be described as exemplary. The solution will be applicable, possibly with some adaptations, to a wide range of problems. It will be generalizable not because of the form it takes (e.g. "All $\mathrm{x}$ are y"), but because causal and normative reality is structured in such a way that there are a lot of similar problems which often require similar solutions.

\section{Conclusion}

Universally true generalizations from which specific conclusions can be deduced are extremely useful to practitioners. Unfortunately they are often not available. Faced with deficiencies in academic or scientific theory, practitioners have the option of engaging in case-based reasoning, or of proposing causal principles of limited scope. These causal principles can be generalized through abstraction, and the difference between them and the causal theory of an academic body of knowledge will be just one of degree and scope. They form parts of a continuum.

The aim of the practitioner will often be to develop a theory about how to solve a problem. These practitioner theories can be encapsulated in design patterns, which may include references to universal generalizations, models, appropriate cases, practitioner knowledge of causes and effects, normative goals and principles, and the skills needed to implement the solution. Design patterns provide a means of reusing past solutions and avoiding the need to constantly return to first principles. They can provide a data structure focused on the solution of common vocational problems. Reasoning from particular cases or design patterns will be primarily by the use of analogy. The more problem solutions an expert practitioner is aware of, the better is his or her problem solving ability likely to be.

One merit of this way of thinking is that it should be easily recognizable by the practitioner. He or she may not use terms like analogical reasoning or abstraction, but it should not be a difficult task, for example, to draw a practitioner's attention to the way in which he or she argues that similar problems require similar solutions. Describing the causal knowledge which academics and practitioners possess does not require exotic classification systems which separate vertical and horizontal knowledge. We should not violate our common sense way of describing things where there is no particular gain (Pring, 1977). 
This paper makes no assumptions about where vocational education takes place. It could be in an educational institution or in the workplace. However, the study of exemplary problems and solutions, which can later be used as the basis for analogical reasoning, can be an important part of vocational education, wherever it is delivered.

\section{References:}

1. Alexander, C., Ishikawa, S. \& Silverstein, M. (1977). A pattern language. New York, NY: Oxford University Press.

2. Bach, T. (2012). Analogical cognition: Applications in epistemology and the philosophy of mind and language. Philosophy Compass 7 (5), 348-360.

3. Bailer-Jones, D. (2009). Scientific models in philosophy of science. Pittsburgh, PA: University of Pittsburgh Press.

4. Bailey, C. (1984). Beyond the present and the particular: A theory of liberal education. London, England: Routledge \& Kegan Paul.

5. Barnes, L., Christensen, R. \& Hansen, A. (1994). Teaching and the case method. Boston, MA: Harvard Business School Press.

6. Barrows, H. \& Pickell, G. (1991). Developing clinical problemsolving skills: A guide to more effective diagnosis and treatment. New York, NY: Norton.

7. Bartha, P. (2010). By parallel reasoning: The construction and evaluation of analogical arguments. New York: Oxford University Press.

8. Bergin (2012). Pedagogical patterns: advice for educators. New York, NY: Joseph Bergin Software Tools.

9. Bergmann, R, \& Wilke, W (2005). On the role of abstraction in casebased reasoning. Lecture Notes in Computer Science 1168, 28-43.

10. Bergmann, R., Kolodner, J. \& Plaza, E. (2006). Representation in case-based reasoning. The Knowledge Engineering Review, 20 (3), 209-213.

11. Bernstein, B. (1999). Vertical and horizontal discourse: An essay. British Journal of Sociology of Education 20 (2), 157-173.

12. Cartwright, N. (1983). How the laws of physics lie. New York, NY: Oxford University Press.

13. Cartwright, N. (1999). The dappled world: A study of the boundaries of science. Cambridge, England: Cambridge University Press.

14. Cross, R. (1968). Precedent in English law. London: Oxford University Press.

15. Dewey, J. (1939). Theory of valuation. In O.Neurath (Ed.), International encyclopedia of unified science, Volume 2 Number 4 (pp.1-67). Chicago, IL: University of Chicago Press. 
16. Didierjean, A. \& Cauzinille-Marmèche, E. (1998). Reasoning by analogy: Is it schema-mediated or case-based? European Journal of Psychology of Education 13 (3), 385-398.

17. Dresch, A., Lacerda, D. \& Antunes Jr., J. (2015). Design science research: a method for science and technology advancement. Cham, Switzerland: Springer.

18. Dunbar, K. (2001). The analogical paradox: Why analogy is so easy in naturalistic settings yet so difficult in the psychological laboratory. In D.Gentner, K.Holyoak \& B.Kokinov (Ed.), The analogical mind (pp.313-334). Cambridge, MA: MIT Press.

19. Dunbar, K, \& Blanchette, I (2001). The in vivo / in vitro approach to cognition: The case of analogy. Trends in Cognitive Sciences 5 (8), 334-339.

20. Gamble, J. (2006). Theory and practice in the vocational curriculum. In M.Young \& J.Gamble, (Eds.), Knowledge, curriculum and qualifications for South African further education (pp.87-103). Cape Town, South Africa: Human Sciences Research Council Press.

21. Gamma, E., Helm, R., Johnson, R. \& Vissides, J. (1994). Design patterns: Elements of reusable object-oriented software. Upper Saddle River, NJ: Addison-Wesley.

22. Gentner, D. \& Colhoun, J. (2010). Analogical processes in human thinking and learning. In B.Gladzeder, V.Goel \& A.von Müller (Eds.), Towards a theory of thinking: Building blocks for a conceptual framework (pp.35-48). Berlin, Germany: Springer.

23. Goswami, U. (1992). Analogical reasoning in children. Hove, England: Lawrence Erlbaum Associates.

24. Goswami, U. (2001). Analogical reasoning in children. In D.Gentner, K.Holyoak \& B.Kokinov (Eds.), The analogical mind (pp.437-470). Cambridge, MA: MIT Press.

25. Guile, D. (2014). Professional knowledge and professional practice as continuous recontextualisation. In M.Young \& J.Muller (Eds.), Knowledge, expertise and the professions (pp.78-92). Abingdon, England: Routledge.

26. Hedstrom, \& Vlikoski, (2010). Causal mechanisms in the social sciences. Annual Review of Sociology 36, 49-67.

27. Hevner, A., March, S. \& Park, J. (2004). Design science in information systems research. MIS Quarterly 28 (1), 75-105.

28. Hofstadter, D. \& Sander, E. (2013). Surfaces and essences: Analogy as the fuel and fire of thinking. Oxford, England: Oxford University Press. 
29. Holyoak, K. (2013). Analogy and relational reasoning. In K.Holyoak \& R.Morrison (Eds.), The Oxford handbook of thinking and reasoning (pp.234-259). Oxford, England: Oxford University Press.

30. Holyoak, K. \& Thagard, P. (1995). Mental leaps: Analogy in creative thought. Cambridge, MA : MIT Press.

31. Hordern, J. (2014). How is vocational knowledge recontextualised? Journal of Vocational Education \& Training 66 (1), 22-38.

32. Jacob, M. (2014). Precedents and case-based reasoning in the European Court of Justice. Cambridge, England: Cambridge University Press.

33. Johannesson, P. \& Perjons, E. (2012). A design science primer. North Charleston, SC: CreateSpace.

34. Josephson, J. \& Josephson, S. (1996). Abductive inference: Computation, philosophy, technology. Cambridge, England: Cambridge University Press.

35. Kingsley, P. (2015). An andragogical design pattern for asynchronous online discussions. In M.King, R.Lock, R.Dawson, M.Ross, G.Staples, J.Uhomoibhi (Eds.), Outlook on computing education: Proceedings of INSPIRE XX, Loughborough University (pp.63-73). Swindon, England: BCS and Southampton Solent University.

36. Kohls, K. \& Wedekind, J. (2011). Perspectives on patterns. In K.Kohls \& J.Wedekind (Eds.), Investigations of e-learning patterns: Context factors, problems and solutions (pp.1-18). Hershey, PA: Information Science Reference.

37. Kolodner, J. (1992). An introduction to case-based reasoning. Artificial Intelligence Review 6, 3-34.

38. Kolodner (1997). Educational implications of analogy: A view from case-based reasoning. American Psychologist 52 (1), 57-66.

39. Lancaster, J. \& Kolodner, J. (1987). Problem solving in a natural task as a function of experience. Alexandria, VA: US Army Research Institute for the Behavioral and Social Sciences.

40. Laurillard, D. (2012). Teaching as a design science: Building pedagogical patterns for learning and technology. Abingdon, England: Routledge.

41. Laurillard, D. \& Ljudojevic, D. (2011). Evaluating learning designs through the formal representation of pedagogical patterns. In K.Kohls \& J.Wedekind (Eds.), Investigations of e-learning patterns: context factors, problems and solutions (pp.86-105). Hershey, PA: Information Science Reference.

42. Layton, D. (1993). Technology's Challenge to Science Education. Buckingham, England: Open University Press. 
43. Lee, H, \& Holyoak, K. (2008). The role of causal models in analogical inference. Journal of Experimental Psychology, Learning, Memory and Cognition 34 (5), 1111-1122.

44. Levinson, M. \& Fay, J. (2016). Introduction. In M.Levinson \& J.Fay (Eds.), Dilemmas of educational ethics: Cases and commentaries (pp.1-8). Cambridge, MA: Harvard University Press.

45. Lucas, B., Spencer, E., \& Claxton, G. (2012). How to teach vocational education: A theory of vocational pedagogy. London, England: City \& Guilds Centre for Skills Development.

46. Mason, R. (1994). Morality and models. In W.Wallace (Ed.), Ethics in modeling (pp.183-194). Kidlington, England: Pergamon.

47. McKenney, S. \& Reeves, T. (2012). Conducting educational design research. Abingdon, England: Routledge.

48. Merton, R. (1949/2012). On sociological theories of the middle range. In C.Calhoun, J.Gerteis, J.Moody, S.Pfaff, \& J.Virk (Eds.), Classical sociological theory (pp.531-542). Chichester, England: Wiley-Blackwell.

49. Mor, Y, \& Winters, N. (2007). Design approaches in designenhanced learning. Interactive Learning Environments 15 (1), 61-75.

50. Nosofsky, R. (2011). The generalized context model: An exemplar model of categorization. In E.Pothos \& A.Wills (Eds.), Formal approaches in categorization (pp.18-39). Cambridge, England: Cambridge University Press.

51. Orr, J. (1996). Talking about machines: An ethnography of a modern job. New York, NY: Cornell University Press.

52. Pring, R. (1977). Common sense and education. Journal of Philosophy of Education 11 (1), 57-77.

53. Richter, I. \& Weber, R. (2013). Case-based reasoning: A textbook. Heidelberg, Germany: Springer.

54. Rippin, A., Booth, C., Bowie, S. \& Jordan, J. (2002). A complex case: using the case study method to explore uncertainty and ambiguity in undergraduate business education. Teaching in Higher Education 7 (4), 429-441.

55. Rosch, E. \& Mervis, C. (1975). Family resemblances: Studies in the internal structure of categories. Cognitive Psychology 7, 573-605.

56. Ross, B. \& Kennedy, P. (1990). Generalizing from the use of earlier examples in problem solving. Journal of Experimental Psychology, Learning, Memory and Cognition 16 (1), 42-55.

57. Saitta, L. \& Zucker, J-D. (2013). Abstraction in artificial intelligence and complex systems. New York, NY: Springer.

58. Savery, J. (2015). Overview of problem-based learning: Definitions and distinctions. In A.Walker, H.Leary, C.Hmelo-Silver \& P.Ertmer 
(Eds.), Essential readings in problem-based learning: Exploring and extending the legacy of Howard S.Barrows (pp.5-15). West Lafayette, IN: Purdue University Press.

59. Schon, D. (1991). The reflective practitioner: How professionals think in action. Farnham, England: Ashgate.

60. Shelley, C. (2002). Analogy counterarguments and the acceptability of analogical hypotheses. British Journal for the Philosophy of Science 53, 477-496.

61. Simon, H. (1981). The sciences of the artificial. Cambridge, MA: MIT Press.

62. Van Aken, J. (2004). Management research based on the paradigm of the design sciences: The quest for field-tested and grounded technological rules. Journal of Management Studies 41 (2), 219-246.

63. Van Aken, J., Berends, H. \& van der Bijl, H. (2011). Problem solving in organizations: A methodological handbook for business students. New Delhi, India: Cambridge University Press.

64. Van den Akker, J., Gravemeijer, K., McKenney, S. \& Nieveen, N. (2006). Educational design research. Abingdon, England: Routledge.

65. Van Strien, P. (1997). Towards a methodology of psychological practice: The regulative cycle. Theory Psychology 7 (5), 683-700.

66. Walton, D. (2004). Abductive reasoning. Tuscaloosa, AL: University of Alabama Press.

67. Watson, I. (1997). Applying case-based reasoning: Techniques for enterprise systems. San Francisco, CA : Morgan Kaufmann.

68. Weinreb, L. (2005). Legal reason: the use of analogy in legal argument. New York, NY: Cambridge University Press.

69. Weisberg, M. (2013). Simulation and similarity: Using models to understand the world. Oxford, England: Oxford University Press.

70. Wieringa, R. (2014). Design science methodology for information systems and software engineering. Heidelberg, Germany: Springer.

71. Winch, C. (2010). Dimensions of expertise: A conceptual exploration of vocational knowledge. London, England: Continuum.

72. Wittgenstein, L. (1958). Philosophical investigations. Oxford, England: Basil Blackwell.

73. Yin, R. (2003). Case study research: Design and methods. Thousand Oaks, California: Sage Publications.

74. Young, M. (2006). Conceptualising vocational knowledge: Some theoretical considerations. In M.Young \& J.Gamble (Eds.), Knowledge, curriculum and qualifications for South African further education (pp.104-124). Cape Town, South Africa: Human Sciences Research Council Press. 